\title{
Kekerasan mikro resin komposit packable dan bulkfill dengan kedalaman kavitas berbeda
}

\author{
Diatri Nari Ratih* dan Andina Novitasari** \\ *Departemen Konservasi Gigi, Fakultas Kedokteran Gigi, Universitas Gadjah Mada, Yogyakarta, Indonesia \\ **Praktek Swasta, Semarang, Jawa Tengah, Indonesia \\ *JI Denta No 1, Sekip Utara, Yogyakarta, Indonesia; e-mail: trinaugm@yahoo.com
}

Submisi: 6 Maret 2017; Penerimaan: 4 Mei 2017; Publikasi online: 31 Agustus 2017

\begin{abstract}
ABSTRAK
Restorasi resin komposit dengan bulkfill semakin populer karena material tersebut dapat disinar dengan ketebalan sampai $4 \mathrm{~mm}$, sehingga mudah diaplikasikan. Tujuan dari penelitian ini adalah untuk mengetahui perbedaan kekerasan mikro restorasi resin komposit packable dan bulkfill dengan kedalaman kavitas $2 \mathrm{~mm}$ dan $4 \mathrm{~mm}$. Penelitian ini dilakukan dengan menggunakan 32 cetakan Teflon (diameter $5 \mathrm{~mm}$ ), dan dikelompokkan secara random menjadi 4 kelompok yang masing-masing terdiri dari 8 sampel. Kelompok $1 \mathrm{~A}$, cetakan diaplikasikan resin komposit packable dengan kedalaman kavitas $2 \mathrm{~mm}$. Kelompok 1B, diaplikasikan komposit bulkfill dengan kedalam $2 \mathrm{~mm}$. Kelompok 2A, diaplikasikan komposit packable dengan kedalaman $4 \mathrm{~mm}$. Kelompok 2B, diaplikasikan komposit bulkfill dengan kedalaman $4 \mathrm{~mm}$. Setiap sampel direndam dalam saliva buatan dengan $\mathrm{pH} 6,8$ dan disimpan dalam inkubator dengan suhu $37^{\circ} \mathrm{C}$ selama 24 jam. Setiap sampel diuji kekerasannya menggunakan Vickers indenter microhardness tester. Data yang diperoleh dianalisis dengan ANOVA dua jalur, dilanjutkan uji Tukey's. Hasil penelitian menunjukkan resin komposit bulkfill dengan kedalaman kavitas $2 \mathrm{~mm}$ memiliki rerata kekerasan mikro tertinggi $(31,09 \pm 2,02 \mathrm{VHN})$, diikuti oleh resin komposit packable dengan kedalaman $2 \mathrm{~mm}(17,52 \pm 1,25 \mathrm{VHN})$, bulkfill dengan kedalaman $4 \mathrm{~mm}(11,97 \pm 1,23 \mathrm{VHN})$ dan packable dengan kedalaman $4 \mathrm{~mm}(3,18 \pm 0,85 \mathrm{VHN})$. Analisis ANOVA dua jalur menunjukkan bahwa terdapat perbedaan yang signifikan antara jenis resin komposit dan antara kedalaman kavitas $(p<0,05)$, serta terdapat interaksi antara jenis resin komposit dan kedalaman kavitas $(p<0,05)$. Kesimpulannya, kekerasan mikro resin komposit packable lebih rendah dibandingkan bulkfill baik pada kedalaman kavitas 2 dan $4 \mathrm{~mm}$.
\end{abstract}

Kata kunci: bulkfill; kedalaman kavitas; kekerasan mikro; packable; resin komposit

\begin{abstract}
Microhardness of packable and bulkfill composite resin with different cavity depths. Bulkfill composite resin restorations are increasingly popular because the material can be irradiated with a thickness reaching 4 $\mathrm{mm}$, making it easier to apply. The objective of this study was to determine the differences in the microhardness between packable and bulkfill composite resin restorations with a cavity depth of $2 \mathrm{~mm}$ and $4 \mathrm{~mm}$. This study was done using 32 Teflon molds ( $5 \mathrm{~mm}$ diameter), and grouped randomly into 4 groups in which each consisted of 8 samples. Group $1 \mathrm{~A}$, packable composite resin was applied to the mold with a cavity depth of $2 \mathrm{~mm}$. Group 1B, bulkfill composite resin was applied to the mold with a cavity depth of $2 \mathrm{~mm}$. Group $2 A$, packable composite resin was applied with a depth of $4 \mathrm{~mm}$. Group 2B, bulkfill composite resin was applied with a depth of $4 \mathrm{~mm}$. Each sample was immersed in artificial saliva with a pH of 6.8 and stored in an incubator at a temperature of $37^{\circ} \mathrm{C}$ for 24 hours. The hardness of each sample was tested using Vickers indenter microhardness tester. The data obtained were then analyzed by using two-way ANOVA, followed by Tukey's test. The results showed that bulfill composite resin with a cavity depth of $2 \mathrm{~mm}$ has the highest average of microhardness (31.09 $\pm 2.02 \mathrm{VHN})$, followed by packable composite resin with a depth of $2 \mathrm{~mm}$ $(17.52 \pm 1.25 \mathrm{VHN})$, bulkfill with a depth of $4 \mathrm{~mm}(11.97 \pm 1.23 \mathrm{VHN})$ and packable with a depth of $4 \mathrm{~mm}(3.18 \pm 0.85$ $V H N)$. The two-way ANOVA analysis showed that there are significant differences between the types of composite resin and cavity depths $(p<0.05)$, and there is interaction between the types of composite resin and cavity depth $(p<0.05)$. In conclusion, the microhardness of packable composite resin is lower than that of bulkfill at a cavity depth of 2 and $4 \mathrm{~mm}$.
\end{abstract}

Keywords: bulkfill; cavity depth; microhardness; packable; composite resin

\section{PENDAHULUAN}

Restorasi resin komposit untuk gigi posterior semakin populer dengan kemajuan penggunaan bahan adhesif di kedokteran gigi. Sebelumnya resin komposit mempunyai sifat kurang tahan terhadap keausan, sehingga kurang bagus apabila digunakan untuk gigi posterior. Saat ini perkembangan resin komposit sangat cepat terutama dalam sistem adhesif, matriks resin, dan ukuran filler, maka penggunaan resin komposit 
untuk gigi posterior semakin meningkat. Hal ini disebabkan semakin meningkatnya permintaan masyarakat untuk direstorasi dengan bahan yang sewarna dengan gigi. ${ }^{1}$

Akhir 1990an diperkenalkan resin komposit packable yang mempunyai viskositas tinggi dan diindikasikan untuk gigi posterior. Resin komposit packable merupakan resin komposit yang rigid, dan tidak lengket pada instrumen saat diaplikasikan dibanding resin komposit yang sebelumnya telah beredar di pasaran. Hal ini disebabkan karena perubahan morfologi filler atau monomer matriksnya. Resin komposit ini sering digunakan sebagai pengganti amalgam. ${ }^{2}$

Penelitian sebelumnya menunjukkan bahwa transisi sinar dari light curing unit menurun intensitasnya setelah melalui bahan resin komposit, sehingga mengakibatkan derajad polimerisasi resin komposit menurun dengan semakin jauhnya jarak sumber sinar dengan permukaan yang disinar. ${ }^{3}$ Penurunan derajad polimerisasi akan mengakibatkan sifat-sifat fisik resin komposit menurun, dan banyak terbentuk monomer sisa yang selanjutnya akan mengakibatkan kegagalan resorasi maupun mempengaruhi jaringan pulpa. ${ }^{4,5}$ Resin komposit dianjurkan untuk diaplikasikan ke dalam kavitas dengan cara incremental (berlapis) dan di sinar dengan ketebalan $2 \mathrm{~mm}$ setiap lapisannya..$^{5,6}$

Restorasi kavitas yang dalam dengan cara berlapis mempunyai kelebihan yaitu penetrasi sinar dapat menyeluruh sehingga polimerisasi dapat optimal. Polimerisasi yang optimal akan menghasilkan sifat fisik yang baik, adaptasi margin meningkat, dan toksisitas menurun dengan berkurangnya monomer sisa. ${ }^{5,6}$ Teknik berlapis juga dapat menurunkan terjadinya pengerutan polimerisasi, sehingga tekanan pengerutan dapat berkurang. Tekanan pengerutan dapat menyebabkan sensitivitas, keretakan mikro pada resin atau struktur gigi, dan kebocoran mikro. ${ }^{2}$

Di klinik, teknik aplikasi berlapis akan sangat menyita waktu apabila digunakan untuk merestorasi kavitas yang luas dan dalam, selain itu mudah terbentuk gelembung udara, terkontaminasi saliva, dan terbentuknya void diantara waktu aplikasi kemungkinan lebih besar. Hal ini dapat mengakibatkan gigi sensitif pasca restorasi, karies sekunder, dan fraktur. ${ }^{7}$

Bahan resin komposit dikembangkan terus terutama dalam hal filler, matriks maupun inisiatornya. Akhir-akhir ini diperkenalkan tipe resin komposit baru yang dinamakan bulkfill. Resin komposit jenis ini menurut produsennya dapat disinar dengan ketebalan sampai $4 \mathrm{~mm}$. Hal ini dikarenakan resin jenis ini bersifat translusen, sehingga transmisi sinar dari light curing unit dapat melewati keseluruhan ketebalan resin komposit. ${ }^{8,9}$ Kelebihan lain dari resin komposit jenis bulkfill adalah mudah diaplikasikan, tidak terbentuk void, pengerutan polimerisasi rendah, sehingga mengurangi terjadi kebocoran mikro, dan mengurangi tekanan pengerutan karena mempunyai elastisitas tinggi. ${ }^{10}$

Kekerasan mikro merupakan salah satu indikator penting dalam bidang kedokteran gigi untuk mengetahui sifat mekanis suatu bahan terhadap ketahanan, keausan, dan abrasi. Kekerasan mikro juga dihubungkan dengan kekakuan dan kekuatan suatu bahan.11,12 Kekerasan mikro suatu bahan restorasi akan mempengaruhi daya tahan bahan restorasi untuk jangka panjang di dalam rongga mulut. Nilai kekerasan mikro untuk bahan resin komposit dapat menentukan derajad polimerisasinya, sehingga sangat berguna untuk mengetahui kekerasan mikro suatu bahan tersebut apabila bahan tersebut digunakan di klinik. ${ }^{7} \mathrm{Hal}$ ini disebabkan karena polimerisasi yang tidak adekuat dapat menghasilkan monomer sisa tinggi yang dapat mengiritasi jaringan pulpa, menstimulasi pertumbuhan bakteri, dan akhirnya berpengaruh terhadap kesuksesan restorasi di klinik. 5,13

Akhir-akhir ini penelitian mengenai resin komposit bulkfill banyak dilakukan, karena bahan ini termasuk bahan restorasi di bidang kedokteran gigi yang baru diperkenalkan beberapa tahun terakhir ini. Resin komposit jenis ini menunjukkan banyak sifat menguntungkan terutama apabila digunakan untuk merestorasi gigi posterior, sehingga perlu dilakukan penelitian mengenai kekerasan resin komposit bulkfill dan resin komposit packable yang banyak beredar di pasaran. Tujuan penelitian ini adalah untuk mengetahui perbedaan kekerasan 
mikro restorasi resin komposit packable dan bulkfill dengan kedalaman kavitas $2 \mathrm{~mm}$ dan 4 $\mathrm{mm}$. Hipotesis dari penelitian ini adalah terdapat perbedaan kekerasan mikro antara restorasi resin komposit packable dan bulkfill.

\section{METODE PENELITIAN}

Tiga puluh dua cetakan Teflon (diameter $5 \mathrm{~mm}$ dan kedalaman $2 \mathrm{~mm}$ atau $4 \mathrm{~mm}$ ) dibagi secara random menjadi dua kelompok yaitu kelompok 1 diaplikasikan resin komposit packable (Tetric N Ceram, Ivoclar Vivadent, Liechteinstein, Jerman) sebanyak 16 cetakan. Kelompok 1 dibagi lagi menjadi kelompok $1 \mathrm{~A}$ yang kedalaman kavitasnya $2 \mathrm{~mm}$ (8 cetakan), dan kelompok $1 \mathrm{~B}$ yang kedalaman kavitasnya $4 \mathrm{~mm}$ (8 cetakan). Kelompok 2 diaplikasikan resin komposit bulkfill (Tetric $N$ Ceram Bulkfill, Ivoclar Vivadent) sebanyak 16 cetakan. Kelompok 2 dibagi lagi menjadi kelompok $2 \mathrm{~A}$ yang kedalaman kavitasnya 2 $\mathrm{mm}$ (8 cetakan), dan kelompok $2 \mathrm{~B}$ yang kedalaman kavitasnya $4 \mathrm{~mm}$ (8 cetakan).

Aplikasi resin komposit dilakukan secara bulk (satu kali aplikasi) dengan plastis instrumen pada masing-masing cetakan dan dikondensasi dan diratakan menggunakan kondensor sampai penuh. Pelat kaca yang diberi beban anak timbangan (500 gram) diletakkan pada masing-masing cetakan untuk mendapatkan kepadatan resin komposit yang sama. Selanjutnya pelat kaca diambil dari permukaan cetakan resin komposit, dan dilakukan penyinaran dengan light curing unit tipe LED (Bluephase, Ivoclar-Vivadent) dengan intensitas sinar $1.100 \mathrm{~mW} / \mathrm{cm}^{2}$ selama 10 detik, dengan arah sinar tegak lurus dengan tumpatan dan dengan jarak satu lembar pita seluloid antara tumpatan dan sumber sinar. Setelah penyinaran pita seluloid diambil dan sampel dikeluarkan dari cetakan.

Seluruh sampel direndam dalam kontainer yang berisi saliva tiruan selama 24 jam untuk mensimulasi keadaan di dalam mulut, dan selama perendaman disimpan dalam inkubator dengan suhu $37^{\circ} \mathrm{C}$. Setelah 24 jam, sampel diambil dan dikeringkan dengan kertas tisu. Selanjutnya cetakan resin komposit diletakkan dan dijepit pada papan mesin pengukur, sehingga permukaan cetakan yang akan diukur terletak tegak lurus dengan aksis indenter. Seluruh sampel kemudian diuji kekerasannya menggunakan Vickers indenter microhardness tester (Shimadzu, Kyoto, Jepang) dengan beban 100 gram selama 20 detik. ${ }^{14}$

Tiga indentasi dibuat pada permukaan yang jauh dari sumber sinar yaitu satu indentasi dibuat tepat di tengah sampel, dan dua indentasi dibuat di sebelah tepi dari sampel. Selanjutnya, hasil dari tiga indentasi dirata-rata untuk mendapatkan satu nilai kekerasan mikro setiap sampel. Nilai kekerasan mikro diperoleh dengan mengukur panjangnya indentasi dengan bantuan mikroskop yang merupakan satu kesatuan dengan alat Vickers indenter microhardness tester. Vickers micro-hardness tester secara otomatis mengolah data dan didapatkan nilai kekerasan setiap sampel dalam satuan Vickers Hardness Number (VHN). Data yang diperoleh dianalisis menggunakan ANOVA dua jalur, dilanjutkan dengan uji Tukey's dengan derajad kemaknaan $95 \%$.

\section{HASIL PENELITIAN}

Hasil penelitian menunjukkan (Gambar 1) bahwa resin komposit bulkfill dengan kedalaman kavitas $2 \mathrm{~mm}$ menghasilkan nilai rerata kekerasan mikro tertinggi $(31,09 \pm 2,02 \mathrm{VHN})$, diikuti oleh resin komposit packable dengan kedalaman kavitas 2 $\mathrm{mm}(17,52 \pm 1,25 \mathrm{VHN})$, dan resin komposit bulkfill dengan kedalaman kavitas $4 \mathrm{~mm}(11,97 \pm 1,23$ VHN). Resin komposit packable dengan kedalaman kavitas $4 \mathrm{~mm}$ menghasilkan nilai kekerasan terendah $(3,18 \pm 0,85 \mathrm{VHN})$.

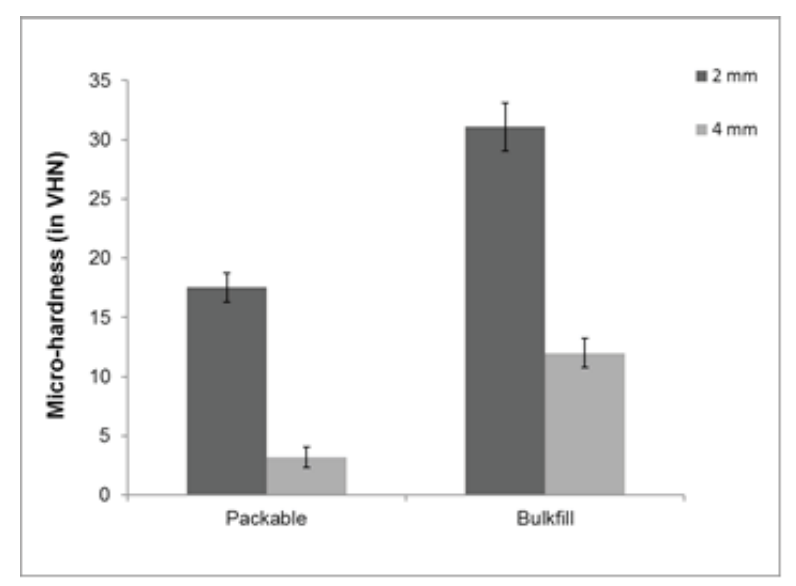

Gambar 1. Rerata dan standard deviasi kekerasan mikro resin komposit packable dan bulkfill dengan kedalaman kavitas $2 \mathrm{~mm}$ dan $4 \mathrm{~mm}$ (dalam VHN) 
Hasil analisis statistik ANOVA dua jalur dan uji Tukey's menunjukkan bahwa terdapat perbedaan yang signifikan antara jenis resin komposit packable dan bulkfill $(p<0,05)$, maupun antara kedalaman kavitas $2 \mathrm{~mm}$ dan $4 \mathrm{~mm}(p<0,05)$. Hasil perhitungan statistik menunjukkan ada interaksi antara jenis resin komposit dengan kedalaman kavitas $(p<0,05)$.

\section{PEMBAHASAN}

Hasil penelitian ini sesuai dengan hipotesis yang diajukan yaitu terdapat perbedaan kekerasan mikro antara restorasi resin komposit packable dan bulkfill. Hal ini disebabkan karena resin komposit bulkfill mempunyai kekerasan yang lebih tinggi diakibatkan oleh derajad polimerisasi yang tinggi. Derajat polimerisasi dapat dihubungkan dengan kekerasan suatu bahan. Semakin tinggi derajat polimerisasi suatu bahan maka semakin meningkat kekerasannya. ${ }^{4,15}$ Derajat polimerisasi dapat dipengaruhi oleh beberapa faktor seperti jumlah, ukuran dan tipe filler, ${ }^{16,17}$ shade resin komposit, ${ }^{18}$ tipe fotoinisiator dan konsentrasinya, ${ }^{19}$ kesesuaian indeks refraksi, ${ }^{15,20}$ sumber dan durasi penyinaran. ${ }^{21}$

Kekerasan yang tinggi dari resin komposit bulkfill disebabkan karena resin jenis bulkfill yang digunakan dalam penelitian mempunyai ukuran partikel filler $\leq 400 \mathrm{~nm}$. Sebaliknya resin komposit packable mempunyai ukuran partikel 0,5 - 1,0 $\mu \mathrm{m}$. Hal ini mengakibatkan resin komposit bulkfill dapat ditransmisi sinar lebih besar dibandingkan resin komposit packable karena ukuran partikelnya lebih kecil. ${ }^{22,23}$ Hasil penelitian ini sesuai dengan pernyataan Alrahlah dkk. ${ }^{24}$ bahwa transmisi sinar adalah salah satu faktor penting untuk menghasilkan derajat polimerisasi resin komposit. Semakin sinar dapat bertransmisi melalui resin komposit, maka derajat polimerisasi semakin tinggi. Derajat polimerisasi yang tinggi mengakibatkan kekerasan resin komposit semakin tinggi. ${ }^{23}$ Leprince dkk., ${ }^{19}$ menyatakan bahwa derajad polimerisasi seharusnya dapat menggambarkan keadaan perubahan yang terjadi pada resin komposit pada tahapan pengerasan. Namun uji kekerasan yang digunakan pada penelitian ini tidak dapat menunjukkan perubahan pada tahapan pengerasan yaitu perubahan matriks resin dari fase cairan ke gel maupun dari fase elastis ke fase keras, sehingga penggunaan uji kekerasan untuk menunjukkan seberapa dalam polimerisasi terjadi tidak dapat memberikan gambaran yang sebenarnya mengenai derajat polimerisasi. Derajat polimerisasi akan meningkat apabila lama penyinaran ditingkatkan. ${ }^{25}$

Kekerasan mikro suatu material juga dipengaruhi oleh indeks refraksi antara matriks resin dan partikel filler. Indeks refraksi pada resin komposit bulkfill lebih sesuai yaitu 1,51 dibanding resin komposit packable yang mengandung UDMA sebagai matriks resin dan barium aluminium gelas sebagai filler. Indeks refraksi yang sesuai antara resin matriks dan filler menyebabkan bulkfill lebih translusen dan sifat optis lebih bagus dibanding packable..$^{15,20,26}$ Material yang mempunyai translusensi tinggi maka sinar light curing unit dapat menembus lebih dalam dan tersebar lebih luas. Sebaliknya resin komposit packable yang digunakan pada penelitian ini mempunyai indeks refraksi yang tidak sesuai yaitu 1,33 sehingga sinar menyebar pada interface resin matriks dan filler, yang akhirnya menghasilkan material bersifat opak yang sulit ditembus sinar. Keadaan ini menyebabkan kekerasan mikro resin komposit bulkfill lebih tinggi dibandingkan packable. ${ }^{15,26}$

Penelitian juga menunjukkan perbedaan yang signifikan antara kedalaman $2 \mathrm{~mm}$ dan 4 $m m(p<0,05)$. Hal ini karena sinar ditransmisikan lebih banyak pada kavitas yang kurang dalam dibanding yang lebih dalam. Transmisi sinar pada resin komposit pada kavitas yang semakin dalam akan semakin berkurang. Transmisi sinar yang terjadi pada resin komposit menunjukkan bahwa pada kedalaman $1 \mathrm{~mm}$ dari permukaan yang dekat dengan sumber sinar, transmisi sinar hanya $25 \%$, diikuti $12 \%$ pada kedalaman $2 \mathrm{~mm}$, dan $7 \%$ dengan kedalaman $3 \mathrm{~mm} \cdot{ }^{27}$ Jadi semakin dalam suatu kavitas maka kekerasannya akan semakin rendah. Pada kekerasan yang rendah atau pada polimersiasi resin komposit yang tidak sempurna, maka terlihat bahwa resin komposit masih dalam fase gel, sehingga resin matriks lunak dan mudah untuk digores. ${ }^{18,23}$ 
Penelitian sebelumnya menunjukkan bahwa maksimal ketebalan resin komposit yang bisa ditembus sinar adalah $2 \mathrm{~mm}$, sehingga dianjurkan menggunakan teknik secara berlapis pada kavitas dengan kedalaman lebih dari $2 \mathrm{~mm} \cdot{ }^{6,24}$ Kavitas dengan kedalaman $2 \mathrm{~mm}$ menunjukkan kekerasan yang lebih tinggi dibanding kavitas denga kedalaman $4 \mathrm{~mm}$.

Penelitian juga menunjukkan bahwa resin komposit bulkfill dengan kedalaman kavitas $2 \mathrm{~mm}$ menunjukkan kekerasan paling tinggi dibandingkan resin komposit bulkfill dengan kedalaman kavitas 4 $\mathrm{mm}$ maupun packable dengan kedalaman kavitas 2 dan $4 \mathrm{~mm}$. Keadaan ini menunjukkan permukaan resin komposit yang paling dekat dengan sumber sinar dari light curing unit akan menghasilkan kekerasan yang paling tinggi dibandingkan permukaan yang jauh dari sumber sinar. ${ }^{21}$

Resin komposit bulkfill yang digunakan pada penelitian ini selain mengandung camphorquinone, juga mengandung Ivocerin sebagai inititator booster. ${ }^{10}$ Hal ini menyebabkan resin komposit bulkfill lebih reaktif apabila terpapar sinar light curing unit, sehingga resin komposit dapat berpolimerisasi pada kavitas yang dalam. ${ }^{4}$ Fenomena tersebut kemungkinan dapat pula mengakibatkan resin komposit bulkfill mengalami pengerutan yang besar. Polimerisasi yang terlalu cepat terjadi pada permukaan yang dekat dengan sumber sinar juga dapat menghalangi transmisi sinar yang melalui resin, sehingga dapat menghalangi polimerisasi pada permukaaan yang lebih dalam. ${ }^{16,28} \mathrm{Hal}$ ini dapat menjelaskan mengapa semakin dalam kavitas, semakin rendah kekerasan kedua jenis resin komposit.

Resin komposit packable dalam penelitian ini menunjukkankekerasan yang rendah terutamapada kedalaman kavitas $4 \mathrm{~mm}$. Penelitian menunjukkan bahwa pada dasar kavitas, resin masih belum terpolimerisasi sempurna dengan terlihat adanya area yang lunak pada saat digores dengan alat ekskavator. Sesuai dengan penelitian terdahulu oleh Furry dkk, ${ }^{5}$ Moore dkk, ${ }^{6}$ dan Kiretmichi dkk, ${ }^{7}$ bahwa resin komposit packable sebaiknya diaplikasikan secara berlapis dengan ketebalan $2 \mathrm{~mm}$. Penelitian yang dilakukan ini adalah mengukur kekerasan mikro pada permukaan yang jauh dari sumber sinar. Hal ini dilakukan untuk mengetahui apakah sinar dapat mentransmisi sampai permukaan kavitas yang paling dalam (4 $\mathrm{mm}$ ). Permukaan yang paling dekat dengan sumber sinar tidak dilakukan uji kekerasan, karena menurut penelitian terdahulu hasil uji kekerasaan mikro pada permukaan yang paling dekat dengan sumber sinar adalah yang paling tinggi kekerasannya dan hasilnya tidak sesuai dengan kenyataan yang terjadi di klinik. ${ }^{17,28}$ Hal ini perlu diteliti lebih lanjut mengenai perbedaan kekerasan pada permukaan yang paling dekat dengan sumber sinar dan permukaan yang paling jauh dari sumber sinar dengan beberapa uji seperti uji kekerasan dan kedalaman kuring ISO $4049 .^{5}$

Pengaplikasian resin komposit packable pada penggunaan di klinik harus secara berlapis pada kavitas yang dalam untuk menghasilkan suatu restorasi yang optimal. Selain itu aplikasi secara berlapis juga perlu dilakukan pada restorasi dengan resin komposit bulkfill karena dari penelitian ini juga terlihat bahwa resin komposit bulkfill menunjukan kekerasan yang lebih rendah pada kavitas dengan kedalaman $4 \mathrm{~mm}$ dibanding $2 \mathrm{~mm}$. Meskipun aplikasi secara berlapis sangat menyita waktu serta kemungkinan terjadinya kontaminasi antara lapisan maupun terbentuknya gelembung udara diantara lapisan dapat meningkat, ${ }^{1,29}$ akan tetapi apabila dilakukan dengan berhati-hati dapat meningkatkan kesuksesan restorasi resin komposit packable maupun bulkfill.

\section{KESIMPULAN}

Kesimpulan dari penelitian ini adalah kekerasan mikro resin komposit packable adalah lebih rendah dibandingkan resin komposit bulkfill baik pada kedalaman kavitas $2 \mathrm{~mm}$ maupun $4 \mathrm{~mm}$.

\section{UCAPAN TERIMA KASIH}

Penelitian ini didanai oleh Dana Masyarakat Fakultas Kedokteran Gigi, Universitas Gadjah Mada dengan nomer 4977/KG/KM/2013. 


\section{DAFTAR PUSTAKA}

1. Brackett WW, Browning WD, Brackett MG, Callan RS, Blalock JS. Effect of restoration size on the clinical performance of posterior packable resin composites over 18 months. Op Dent. 2007; 32: 212 - 6.

2. Chesterman J, Jowett A, Gallacher A, Nixon I. Bulk-fill resin-based composite restorative materials: a review. Br Dent J. 2017; 222: 337 -44 .

3. Fujita K, Ikemi T, Nishiyama N. Effects of particles size of silica filler on polymerization conversion in a light curing resin composite. Dent Mater. 2011; 27: $1079-85$.

4. Fleming GJP, Awan M, Cooper PR, Sloan AJ. The potential of a resin composite to be cured to a $4 \mathrm{~mm}$ depth. Dent Mater. 2008; 24: 522 9.

5. Flury $S$, Hayoz $S$, Peutzfeldt A, Husler J, Lussi A. Depth of cure of resin composites: Is the ISO 4049 method suitable for bulkfill materials?. Dent Mater. 2012; 28: 521 - 8.

6. Moore BK, Platt JA, Borges G, Chu TMG, Katsilieri I. Depth of cure of dental resin composites: ISO 4049 depth and microhardness of types of materials and shades. Op Dent. 2008; 33: 408 - 12.

7. Kiremitci A, Alpaslan T, Gusgan S. Six-year clinical evaluation of packable composite restorations. Op Dent. 2009; 34: $11-7$.

8. Czasch P, llie N. In vitro comparison of mechanical properties and degree of cure of bulkfill composites. Clin Oral Invest. 2013; 17 : $227-35$.

9. Van Ende A, De Munck J, Van LK, Poitevin A, Peumans M, Van Meerbeek B. Bulk-Filling of high C-factor posterior cavities: effect on adhesion to cavity-bottom dentin. Dent Mater. 2013; 29: 269 - 77 .

10. Ilie N, Bucuta S, Draenert M. Bulk-fill resinbased composites: An in vitro assessment of their mechanical performance. Op Dent. 2013; 38: $1-8$.
11. Anusavice KJ, Shen C, Rawls HR. Phillips science of dental materials. $12^{\text {th }}$ ed. Philadelphia: Saunders; 2012. $132-50$.

12. Campos EA, Ardu S, Lefever D, Jasse FF, Bortolotto T, Krejci I. Marginal adaptation of class II cavities restored with bulk-fill composites. J Dent. 2014; 42: 575 - 81.

13. El-Safty S, Silikas N, Watts DC. Creep deformation of restorative resin-composites intended for bulk-fill placement. Dent Mater. 2012; 28: 928 - 35.

14. QasimAS, Rahawi OS, Sultan AA. The Effect of in-office tooth whitening on the microhardness of esthetic restoration (An in vitro study). AlRafidain Dent. 2009; 9: 83 - 9.

15. Shortall AC, Palin WM, Burtscher P. Refractive index mismatch and monomer reactivity influence composites curing depth. J Dent Res. 2008; 87: $84-8$.

16. Park J, Chang J, Ferracane J, Lee B. How should composite be layered to reduce shrinkage stress: Incremental or bulk-filling?. Dent Mater. 2008; 24: 1501 - 5.

17. Leprince JG, Palin WM, Vanacker J, Sabbagh J, Devaux J, Leloup G. Physico-mechanical characteristics of commercially available bulkfill composite. J Dent. 2014; 42: 993 - 1000.

18. Bennetti AR, Havndrup-Pedersen C, Honore D, Pedersen MK, Pallesen U. Bulk-fill resin composites: polymerization contraction, depth of cure, and gap formation. Oper Dent. 2015; 40: $190-200$.

19. Leprince JG, Hadis M, Shortall AC, Ferracane JL, Devaux J, Leloup G. Photoinitiator type and applicability of exposure reciprocity law in filled and unfilled photoactive resins. Dent Mater. 2011; 27: 157 - 64.

20. Hakan C, Ertugrul E, Mehmet M, Hamidi. Shear bond strength of bulk-fill and nanorestorative materials to dentin. Eur $\mathrm{J}$ Dent. 2016; $10: 40-5$.

21. Illie N, Stark K. Curing behavior of highviscosity bulk-fill composites. J Dent. 2014; 42: $977-85$. 
22. Furness A, Tadros MY, Looney S, Rueggeber F. Effect of bulk/incremental fill on internal gap formation of bulk-fill composites. J Dent. 2014; 42: $439-49$.

23. Poggio C, Lombardini M, Gaviati S, Chiesa M. Evaluation of Vickers hardness and depth of cure of six composites resins photo-activated with different polymerization modes. J Conserv Dent. 2012; 15: 237 - 41.

24. Alrahlah A, Silikas N, Watts DC. Post-sure depyh of bulk fill dental resin composites. Dent Mater. 2014; 30: 149 - 54.

25. Zorzin J, Maier E, Harre S, Fey T, Belli R, Lohbauer U, Petschelt A, Taschner M. Bulkfill resin composite: Polymerization properties and extended light curing. Dent Mater. 2015; 31: $293-301$.
26. Son SA, Roh HM, Hur B, Kwon YH, Park JK. The effect of resin thickness on polymerization characteristics of silorane-based composite resin. Restor Dent Endod. 2014; 39: 310 - 8.

27. Rueggeberg FA, Cole MA, Looney SW, Vickers A, Swift EJ. Comparison of manufacturerrecommended exposure durations with those determine using biaxial flexure a variety of light-curing units. J Esthet Restor Dent. 2009; 21: $43-61$.

28. Leprince JG, Leveque P, Nysten B, Gallez B, Devaux J, Leloup G. New Insight into the' depth of cure of dimethacrylate-based dental composites. Dent Mater. 2012; 28: 512 - 20.

29. Czasch $P$, llie N. In vitro comparison of mechanical properties and degree of cure of bulkfill composites. Clin Oral Invest. 2013; 17 : $227-35$. 